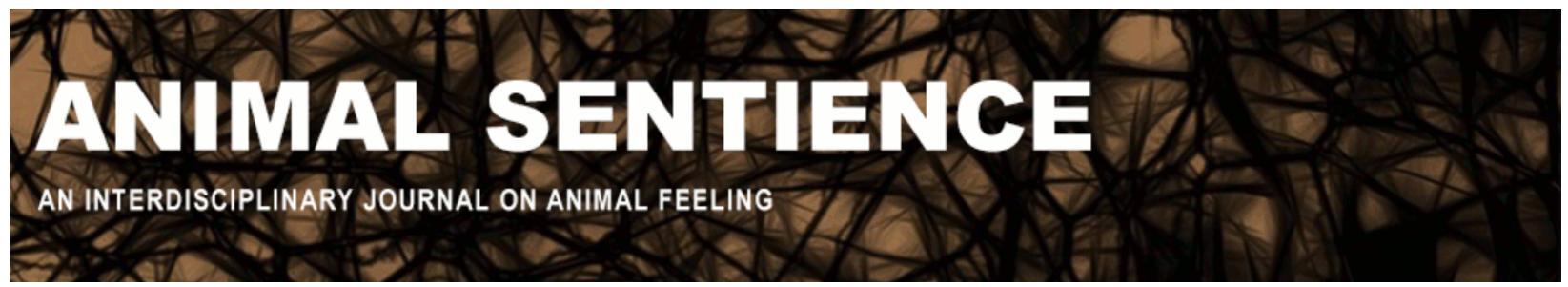

Jones, Robert C. (2017) The precautionary principle: A cautionary note. Animal Sentience 16(15)

DOI: $10.51291 / 2377-7478.1250$

Date of submission: $2017-11-11$

Date of acceptance: 2017-11-17

(c)

This article has appeared in the journal Animal

Sentience, a peer-reviewed journal on animal

cognition and feeling. It has been made open access,

free for all, by WellBeing International and deposited

in the WBI Studies Repository. For more information,

please contact

wbisr-info@wellbeingintl.org.

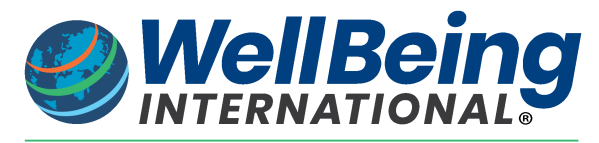

SOLUTIONS FOR PEOPLE, ANIMALS AND ENVIRONMENT 


\title{
The precautionary principle: A cautionary note
}

Commentary on Birch on Precautionary Principle

\author{
Robert C. Jones \\ Department of Philosophy \\ California State University, Chico
}

\begin{abstract}
The precautionary principle regarding animal sentience is often used in decision-making about human actions that may cause harm to nonhuman animals. Birch (2017) develops an account of the precautionary principle requiring two pragmatic rules for its implementation. I support Birch's proposal but offer a cautionary note about relying on precautionary principles if one's ultimate goal is to emancipate animals from human domination.
\end{abstract}

Robert C. Jones is Associate Professor of Philosophy at California State University. He has published numerous articles and book chapters on animal ethics, animal cognition, and food ethics, and has given over forty talks on animal ethics. rcjones.me

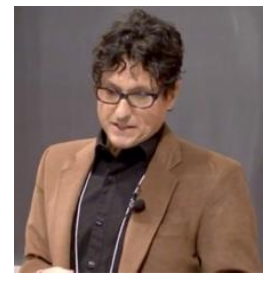

In his target article, Birch (2017) develops an account of the precautionary principle geared specifically to questions of animal sentience in the context of decision-making procedures that concern animal welfare. Birch's formulation - which he calls the "Animal Sentience Precautionary Principle" (ASPP) - requires that "[w]here there are threats of serious, negative animal welfare outcomes, lack of full scientific certainty as to the sentience of the animals in question shall not be used as a reason for postponing cost-effective measures to prevent those outcomes" (p. 3). Grounding the ASPP are two pragmatic rules for its implementation: a sciencebased bar (BAR) providing evidence for attributing sentience to a nonhuman animal; and a practical decision rule (ACT) to guide nonhuman animal protection legislation justified by BAR. The combination of BAR and ACT is intended to provide a practical method for implementing ASPP.

As Birch notes, I myself have invoked the precautionary principle regarding teleost sentience and welfare legislation (Jones 2016). And I am sympathetic to Birch's proposal to develop a robust ASPP, since the current state of global animal welfare legislation relative to even the most rigorously confirmed evidence on animal sentience and cognition is at best regressive (Jones 2013), and, at worst - particularly with regard to food animal legislation in the U.S. - atrocious. But I do want to make just three brief points:

1. Certainty. It's important to highlight Birch's point that, whatever evidentiary BAR we commit to regarding the sentience of a particular animal species (or order), we cannot require anything close to certainty before granting legal protections. A common challenge from skeptics of animal sentience involves questions of the form, "How can one ever really know that species $X$ is 
sentient?" However, that's a very different sense of "know" from the one used in claims of animal sentience (Jones 2014). That's not what scientists who make such claims mean by "know" when they say, for example, that we now know that chickens are sentient. When one asserts that research now supports the claim that teleosts are sentient (Brown 2015; 2016; or Sneddon 2015), it's important to reiterate that this claim is (a) provisional (as are all scientific claims), and (b) justified through inference to the best explanation, a point that Birch makes and one worth reiterating.

2. Burden of proof. It's also important to note that there is a bit of burden shifting going on here. On the one hand, some of us who are concerned with animal welfare may demand a stronger ASPP than the one that Birch proposes, for example:

SASSP: In cases where any uncertainty exists regarding the sentience of a particular species, we ought to treat every member of that species as though they were sentient.

Barring panpsychism, SASPP is implausible, as it would require that we treat every living thing as though they were sentient, an impractical and overly demanding BAR and ACT, to say the least (Fischer 2016).

However, it's worth noting that historically - from the Cartesians to the logical positivists philosophers and scientists writing on and investigating nonhuman animal cognition have assumed an equally strong inverse precautionary principle (a kind of "decautionary" principle), advising that in cases where uncertainty exists about the sentience of a particular species, we should treat each member of that species as though they were not sentient, unless rigorously demonstrated otherwise. But this assumption, like SASPP, is also implausible and unreasonably strong. This decautionary principle is captured most pithily by that fundamental precept of parsimony in comparative psychology, Lloyd Morgan's Canon, according to which, with regard to an animal's behavioral states, "[i]n no case may we interpret an action as the outcome of the exercise of a higher psychical faculty, if it can be interpreted as the outcome of the exercise of one which stands lower in the psychological scale" (as quoted in Rollin 2011, p. 121). (Interestingly, Rollin 2011 presents incontrovertible textual evidence that Morgan's Canon actually assumes the truth of panpsychism.) [See also Rollin 2017, this journal - ed.]

If history is any indication, no matter what evidentiary BAR we choose short of full-blown firstperson introspective, intersubjective verbal self-reports, skeptics will seek (and sometimes find) counterexamples that maintain human exceptionalism. We need not cede ground here, especially given the abysmal, anti-scientific, and downright dangerous record of ignorant and racist scientific pronouncements on the issue of pain attribution in humans (see, for example, Hoffman, Trawalter, Axt, \& Oliver 2016; and Rollin 2006, chapter 9). Theoretically, the scope of views of animal sentience and consciousness can range from philosophical zombism at one extreme, to panpsychism at the other; but why the burden of proof falls closer to the former than the latter cannot, itself, be justified on scientific grounds. Indeed, given that, evolutionarily speaking, pain and suffering are probably very old phenomena, it would be strange if pain were not widespread across varied taxa, did not provide selective advantage, and did not serve an adaptive function similar to whatever adaptive function it serves in humans. Practically speaking, we find this kind 
of commonsense thinking reflected in the British (but not U.S.) Animal Welfare Act which covers "all vertebrates."

3. Necessity. I would be remiss were I to fail to point out that according to the USDA (usda.gov), approximately 42 billion land animals globally (1.02 billion cattle, 1.2 billion pigs, and 40 billion chickens) - vertebrates who we know with near-certainty are sentient - suffer and die for human consumption. Our best theories of science regarding the cognitive and sensitive properties of these beings make unnecessary the implementation of any kind of precautionary principle regarding their abilities to experience pain and suffering. Yet, despite this fact, and despite legislative welfare regulations, these animals suffer unspeakable pain, suffering, and death during their nasty, brutish, and short (but perhaps not short enough) lives. Better science, near-certainty regarding sentience, or increased welfare legislation alone will not end the savagery that is visited upon billions of animals under cover of speciesism and human exceptionalism. That task requires transcending our own bad faith by untelling the stories we tell ourselves about the meaning and necessity of animal pain and suffering. As Sanbonmatsu (2011) argues, "[b]y telling ourselves that we have no 'choice' but to kill and to consume animals, thereby refusing responsibility for our participation in terror, we undermine our claims to being the kind of being that alone can exercise autonomous judgment" (p. 43).

\section{References}

Birch, J. (2017) Animal sentience and the precautionary principle. Animal Sentience 16(1). Brown, C. (2015) Fish intelligence, sentience and ethics. Animal Cognition, 18, 1-17.

Brown, C. (2016) Fish pain: An inconvenient truth. Animal Sentience 3(32).

Fischer, B. (2016) Bugging the strict vegan. Journal of Agricultural and Environmental Ethics, 29(2), 255-263.

Hoffman, K. M., Trawalter, S., Axt, J. R., \& Oliver, M. N. (2016) Racial bias in pain assessment and treatment recommendations, and false beliefs about biological differences between blacks and whites. Proceedings of the National Academy of Sciences, 113(16), 4296-4301.

Jones, R. C. (2013) Science, sentience and animal welfare. Biology and Philosophy, 28, 1-30. Jones, R. C. (2014) "The lobster considered." In Gesturing toward reality: The philosophy of David Foster Wallace. Continuum Press.

Jones, R. C. (2016) Fish sentience and the precautionary principle. Animal Sentience 3(10). Rollin, B. (2006) Science and ethics. Cambridge University Press.

Rollin, B. (2011) Putting the horse before Descartes: My life's work on behalf of animals. Temple University Press.

Rollin, B. (2017) Raising the moral consciousness of science. Animal Sentience 16(8).

Sanbonmatsu, J. (2011) The animal of bad faith: Speciesism as an existential project. In Critical theory and animal liberation, Ed. J. Sorenson, 29-45. New York: Rowman \& Littlefield Publishers.

Sneddon, L. U. (2015) Pain in aquatic animals. Journal of Experimental Biology, 218, 967-976. 